\title{
Cephalic vein transposition: An effective surgical option for dealing with the cephalic vein stenosis
}

Zia Ur Rehman

Aga Khan University, ziaur.rehman@aku.edu

Follow this and additional works at: https://ecommons.aku.edu/pakistan_fhs_mc_surg_surg

Part of the Cardiology Commons, and the Surgery Commons

\section{Recommended Citation}

Rehman, Z. (2020). Cephalic vein transposition: An effective surgical option for dealing with the cephalic vein stenosis. JPMA. The Journal of the Pakistan Medical Association, 70(3), 560-560.

Available at: https://ecommons.aku.edu/pakistan_fhs_mc_surg_surg/803 


\section{Cephalic Vein Transposition: an effective surgical Option for dealing with the cephalic vein stenosis}

Zia Ur Rehman

Madam, Cephalic arch stenosis is a long term complication of brachiocephalic arteriovenous fistula (AVF). It may be present in $19 \%$ to $77 \%$ of the patients with malfunctioning brachiocephalic AVF. ${ }^{1}$ It is suspected by physical examination when a patient has an aneurysmal dilation proximal to cephalic arch and complains of prolonged haemostasis and high venous pressure during dialysis. Percutaneous venoplasty is the treatment but is associated with poor primary patency rates. ${ }^{2}$ Repeated balloon angioplasty is the norm. Surgical option as cephalic arch transposition can be considered for dealing this entity in 'selected' patients.

We report a 29 years old lady with chronic renal failure on haemodialysis who had left brachiocephalic AVF created 1.5 years back. She developed cephalic arch stenosis. She had two sessions of venoplasties for the stenotic segment. This provided partial relieve for few months in between but the symptoms recurred. She presented this time with bleeding from the fistula site, needing manual compression to arrest it. Her recent venogram showed recurrent cephalic arch stenosis and patent central veins (Figure). The narrowed segment was measuring approximately $34 \mathrm{~mm}$ and causing $60-70 \%$ stenosis. As she was young and a good surgical candidate, cephalic arch transposition was planned. The risks and benefits of the procedure were explained to her. The procedure was performed in general anaesthesia. After standard preparation and draping, incision was placed over the cephalic vein at the shoulder joint which was dissected for enough length. Axillary vein was also dissected through a separate incision. Cranial end of the dissected cephalic vein was ligated while distal end of the cephalic vein was

Department of Surgery, Aga Khan University Hospital, Karachi Pakistan.

Correspondence: Zia Ur Rehman. e-mail: drzia7179@gmail.com

brought through subcutaneous tunnel to the axillary vein. An end-to-side anastomosis was created between cephalic and axillary veins using Prolene $6 / 0$. Both wounds were closed in layers. Flow character of the fistula changed from pulsatile to soft thrill and tense fistulous aneurysmal

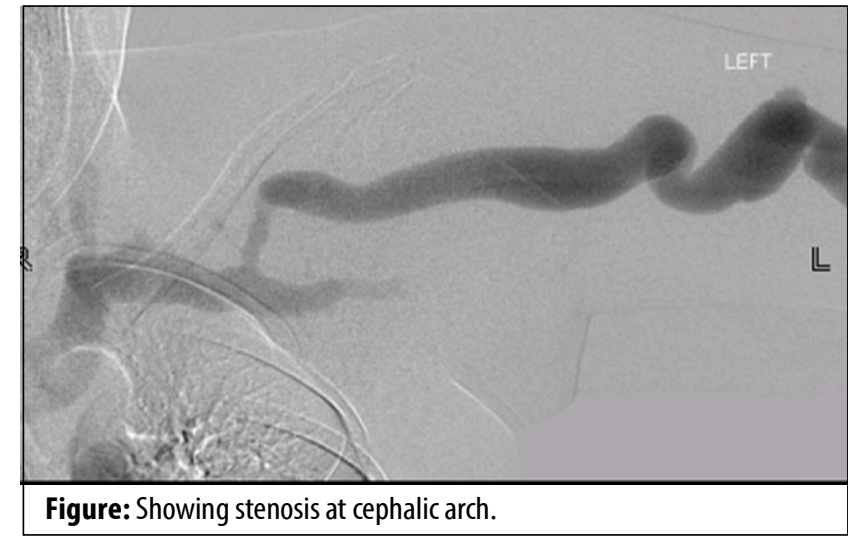

vein segments also relaxed. Patient had dialysis soon after the procedure from the same access site. She had a patent fistula on the follow up visit, 18 months after the index procedure with no complications.

Cephalic arch stenosis is effectively treated by surgical interventions. Venoplasty of the stenotic segments is although minimal invasive but has a shorter patency. ${ }^{3}$ This is partially explained by the fact that angioplasty itself causes intimal damage and accelerates neo-intimal hyperplasia. If the patient is a surgical candidate with good long term expectancy, cephalic vein transposition is an excellent option. ${ }^{4}$

Disclaimer: None to declare.

Conflict of interest: None to declare.

Funding disclosure: None to declare.

\section{References}

1. Jang J, Jung H, Cho J, Kim J, Kim HK, Huh S. Central Transposition of the Cephalic Vein in Patients with Brachiocephalic Arteriovenous Fistula and Cephalic Arch Stenosis. Vasc Specialist Int 2014;30:627.

2. Sivananthan G, Menashe L, Halin NJ. Cephalic arch stenosis in dialysis patients: review of clinical relevance, anatomy, current theories on etiology and management. J Vasc Access 2014;15:15762.

3. Bountouris I, Kritikou G, Degermetzoglou N, Avgerinos Kl. A Review of Percutaneous Transluminal Angioplasty in Hemodialysis Fistula. Int J Vasc Med 2018;2018:e1420136.

4. Henry JC, Sachdev U, Hager E, Dillavou E, Yuo T, Makaroun M, et al. Cephalic vein transposition is a durable approach to managing cephalic arch stenosis. J Vasc Access 2017.

https://doi.org/10.5455/JPMA.50245 